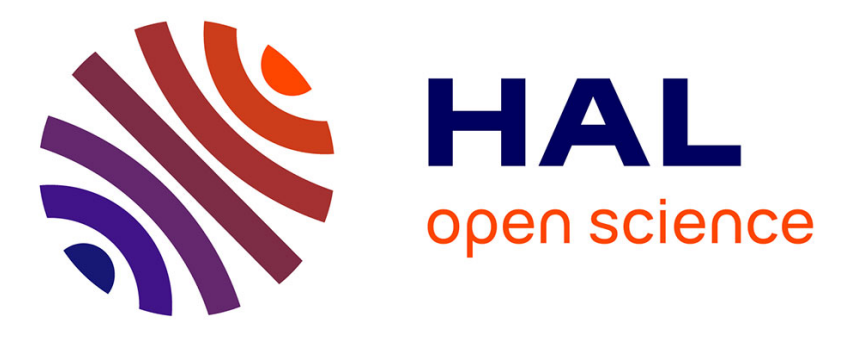

\title{
Integrated product-process design: Material and manufacturing process selection for additive manufacturing using multi-criteria decision making
}

Uzair Khaleeq Uz Zaman, Mickael Rivette, Ali Siadat, Seyed Meysam Mousavi

\section{- To cite this version:}

Uzair Khaleeq Uz Zaman, Mickael Rivette, Ali Siadat, Seyed Meysam Mousavi. Integrated productprocess design: Material and manufacturing process selection for additive manufacturing using multicriteria decision making. Robotics and Computer-Integrated Manufacturing, 2017, 51, pp.169-180. 10.1016/j.rcim.2017.12.005 . hal-02310581

\section{HAL Id: hal-02310581 \\ https://hal.science/hal-02310581}

Submitted on 10 Oct 2019

HAL is a multi-disciplinary open access archive for the deposit and dissemination of scientific research documents, whether they are published or not. The documents may come from teaching and research institutions in France or abroad, or from public or private research centers.
L'archive ouverte pluridisciplinaire HAL, est destinée au dépôt et à la diffusion de documents scientifiques de niveau recherche, publiés ou non, émanant des établissements d'enseignement et de recherche français ou étrangers, des laboratoires publics ou privés. 


\title{
Integrated product-process design: Material and manufacturing process selection for additive manufacturing using multi-criteria decision making
}

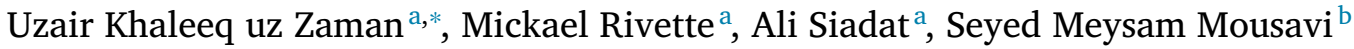 \\ ${ }^{a}$ Laboratoire de Conception Fabrication Commande (LCFC), Ecole Nationale Supérieure d'Arts et Métiers (ENSAM), 4, Rue Augustin Fresnel, 57078, Metz Cedex 3, \\ France \\ ${ }^{\mathrm{b}}$ Department of Industrial Engineering, Faculty of Engineering, Shahed University, Tehran, Iran
}

\begin{abstract}
A B S T R A C T
Market dynamics of today are constantly evolving in the presence of emerging technologies such as Additive Manufacturing (AM). Drivers such as mass customization strategies, high part-complexity needs, shorter product development cycles, a large pool of materials to choose from, abundant manufacturing processes, diverse streams of applications (e.g. aerospace, motor vehicles, and health care) and high cost incurred due to manufacturability of the part have made it essential to choose the right compromise of materials, manufacturing processes and associated machines in early stages of design considering the Design for Additive Manufacturing guidelines. There exists a complex relationship between AM products and their process data. However, the literature to-date shows very less studies targeting this integration. As several criteria, material attributes and process functionality requirements are involved for decision making in the industries, this paper introduces a generic decision methodology, based on multi-criteria decision-making tools, that will not only provide a set of compromised AM materials, processes and machines but will also act as a guideline for designers to achieve a strong foothold in the AM industry by providing practical solutions containing design oriented and feasible material-machine combinations from a current database of 38 renowned AM vendors in the world. An industrial case study, related to aerospace, has also been tested in detail via the proposed methodology.
\end{abstract}

List of Abbreviations

3DP 3D Printing

ABS Acrylonitrile-Butadiene-Styrene

AHP Analytical Hierarchy Process

AM Additive Manufacturing

APF Arburg Plastic Freeforming

CAD Computer-Aided Design

CE Concurrent Engineering

CJP Color Jet Printing

CNC Computer Numeric Control

DfAM Design for Additive Manufacturing

DFM Design for Manufacturability

DLP Digital Light Processing

DMP Direct Metal Printing

EBAM Electron Beam AM

EBM Electron Beam Melting

FDM Fused Deposition Modeling

IPPD Integrated Product-Process Design

$\begin{array}{ll}\text { LENS } & \text { Laser Engineered Net Shaping } \\ \text { LMD } & \text { Laser Metal Deposition } \\ \text { LOM } & \text { Laminated Object Manufacturing } \\ \text { MCDM } & \text { Multi-Criteria Decision Making } \\ \text { MJM } & \text { Multi-jet Modeling } \\ \text { MPS } & \text { Material Process Selection } \\ \text { PC } & \text { Poly-Carbonate } \\ \text { PP } & \text { Poly-Propylene } \\ \text { SAS } & \text { Slide and Separate } \\ \text { SAW } & \text { Simple Additive Weighting } \\ \text { SLA } & \text { Stereolithography } \\ \text { SLM } & \text { Selective Laser Melting } \\ \text { SLS } & \text { Selective Laser Sintering }\end{array}$

\section{Introduction}

Since the inception of Additive Manufacturing (AM) as Stereolithography (SLA) by 3D systems in 1987, AM has taken up a significant and 
impressive compound annual growth rate of $26.2 \%$ to attain a market worth of $\$ 5.165$ billion in 2015 [1]. Reduced product development cycles, increased and revamped regulations on sustainability, increasing demand for personalized and customized products, enhanced part-complexity, reduced lead times and manufacturing cost, increased throughput levels, and the introduction of new business models, are some of the many market factors that have assisted the associated growth of AM to produce complex parts in small to medium sized batches $[2,3]$. Moreover, the quantity and variety of End-of-Life (EoL) products in recent years has demanded the AM production systems to be designed in a sustainable manner such that the economic and environmental impacts are reduced [4]. This also includes the need for post-processing for issues such as removal of powder, support structures, platforms and polishing, as the surface quality may limit the application of the part produced [5]. As a result, the existing vast field of processing technologies and competitors in the hardware space of AM have all been found chasing diverse goals to simultaneously design a product, select a compromised material and pick a suitable fabrication process. This concept further comes under the domain of Concurrent Engineering (CE) and Integrated Design (ID) which help in not only reducing product development time, design rework, and cost, but also in improving communications between different functions of the total product development cycle by making upstream decisions to cater for downstream and external requirements [6,7].

As CE/ID is an attempt towards the integration of product and process plan parameters, the selection of the 'best compromise' of materials and manufacturing processes from a pool of over 80,000 materials, to not only satisfy the customer needs and functional specifications but also account for the process specific constraints, is a daunting task within itself. Some researchers have also referred to conceptual process planning to estimate the manufacturability and cost of conceptual design in early parts of the design stages [8]. But since AM has the capability to operate potentially constraints free, it has invited new heights of design freedom by offering enhanced complexities in terms of shape, multi-scale structures, materials and functionality [9]. It can also build parts in a single operation without wasting much raw material [10]. The subsequent realization has convinced the designers to use the Design for Additive Manufacturing (DfAM) guidelines to develop an integrated approach in the design stage wherein integrated product development teams manage to lessen and even vanish many manufacturing factors and constraints associated with traditional machining, such as, developing a modular design, using standard components, avoiding separate fasteners, and minimizing assembly directions, to attain parts of any geometric complexity without traditional machining aids such as tooling [11-13]. Moreover, as AM has the capacity to fundamentally change the way in which products are made and distributed, it has become a 'disruptive' technology marking its foot hold in nearly all areas of applications. Cotteleer et al. [14] and Sharon [15] divided these into seven areas: aerospace; health care; motor vehicles; consumer products/electronics and academic institutions; industrial applications; architecture; and government/military. Various 'generic' functionality indices and weights concerning multiple design goals, such as energy consumption, material strength, cost, environmental impact, and recyclability, are associated with each of the application areas and need to be taken care of appropriately. Furthermore, the suggestion of the compromised materials and manufacturing processes, referred to as the Material Process Selection (MPS) problem from now on, becomes an interdisciplinary effort keeping in view AM's capacity to be both highly inclined towards CE / ID and governing multiple areas of application. This also proposes that several conflicting criteria will be associated with the MPS problem, which in turn must satisfy product's life cycle requirements. Hence, such problems can be best handled using Multi-Criteria Decision Making (MCDM) methods [16].

Although many AM design guidelines have been published to cater for the process and machine specific constraints for a material, such guidelines could only provide a starting point and do not provide infor- mation about the different kinds of AM machines and their production capabilities [17]. Consequently, the objective of this paper is to provide a new generic decision methodology that can not only consider the interaction between product and process data, but is also be applicable on all areas of application using the MCDM methods; Ashby's material selection charts and Analytical Hierarchy Process (AHP). The former method is utilized for screening of materials while the latter method is utilized for ranking of the combination of materials and manufacturing processes for AM. Combined, the method is called Integrated Product-Process Design (IPPD). Moreover, an AM machine database of 134 renowned machines from 38 international vendors along with AM-specific materials' database is utilized to provide the most feasible material-machine combinations for a given design of product model considering product requirements, attributes and other function-related constraints and objectives. An industrial case study related to the aerospace industry is similarly presented to test the workability of the proposed methodology in detail as well.

The remainder of the paper is divided as follows: Section 2 presents the literature review of the IPPD concept in conjunction with DfAM and its subsequent relation with MCDM techniques related to MPS problem; Section 3 displays the proposed methodology; Section 4 displays the results for an industrial case study; Section 5 provides comparative analysis with another MCDM tool (Simple Additive Weighting), and finally, Section 6 discusses the conclusions drawn for a collaborative product development (considering product and process development).

\section{Literature review}

AM is defined by ASTM as the "process of joining materials to make objects from 3D model data usually layer upon layer, as opposed to subtractive manufacturing technologies like traditional machining" [18]. STL (STereoLithography or Standard Tessellation Language) is the standard file format used on various AM machines but there are other file formats such as SLI, SLC, HPGL, CLI, VRML, 3MF and IGES. Moreover, Monzon et al. [19] split AM in to 7 areas; vat photopolymerization (process that cures a liquid photopolymer contained in a vat by providing energy at specific locations of a cross-section), material jetting (process that uses ink-jet for printing), binder jetting (process which prints a binder in to a powder bed to form a part cross-section), material extrusion (process that makes a part by extruding material through a nozzle), powder bed fusion (process that uses an energy source like a scanning laser to selectively process a container filled with powder), sheet lamination (process that deposits material in form of layers), and directed energy deposition (process that uses a single deposition device to simultaneously deposit material and provide energy to process the material). The associated AM processes for each of the 7 classes are numerous; but, Huang et al. [20] provided a comprehensive overview of all the concerned classes along with their popular associated AM processes, materials used in those machines and their famous manufacturers as depicted in Table 1.

AM has the potential to simultaneously build an object's material and geometry but considering unlimited potential does not guarantee having unlimited capability. The designers working in the AM industry have to not only concentrate on the types of constraints involved in procedures such as Computer Aided Design (CAD) and the digitization of its ideas [20], discretization (digital and physical) of the parts to be produced, assessing capabilities of AM machines, and processing of materials to gauge the impact on properties, but also cater for new challenges and requirements associated with metrology and quality control, maintenance, repair and recycling, lack of generic interdependency between materials and processes, limitation in material selection, longer design cycle than manufacturing cycle, surface finishing issues and postprocessing requirements $[21,22]$. Since, the stakeholders in AM industry related to part manufacture are not altering the design completely in the 'design phase' thereby resulting in an increase in the costs incurred both due to manufacturability and production time, it is highly important to 
Table 1

AM processes, materials and manufacturers -modified from Huang et al. [20].

\begin{tabular}{|c|c|c|c|c|}
\hline Process category & AM process & Material & Manufacturer & Machine examples \\
\hline \multirow[t]{7}{*}{ Vat Photopolymerization } & \multirow[t]{7}{*}{ SLA } & \multirow[t]{5}{*}{ UV curable resins } & Asiga & Freeform Pico \\
\hline & & & 3D systems & iPro \\
\hline & & & & Projet6000/7000 \\
\hline & & & EnvisionTEC & Perfactory \\
\hline & & & Rapidshare & S Series \\
\hline & & Waxes & DWS & DigitalWAX \\
\hline & & Ceramics & Lithoz & CeraFab 7500 \\
\hline \multirow[t]{3}{*}{ Material jetting } & \multirow[t]{3}{*}{ MJM } & UV curable resins & 3D systems & Projet 3500 HD/3510/5000/5500 \\
\hline & & & Stratasys & Objet \\
\hline & & Waxes & Solidscape & $3 Z$ \\
\hline \multirow[t]{3}{*}{ Binder jetting } & \multirow[t]{3}{*}{ 3DP } & Composites & 3D Systems & Z-Corp \\
\hline & & Polymers, ceramics, sand & Voxeljet & VX Series \\
\hline & & Metals & ExOne & M-Flex \\
\hline \multirow[t]{10}{*}{ Material extrusion } & \multirow[t]{9}{*}{ FDM } & Thermoplastics & Stratasys & Dimension \\
\hline & & & & Fortus \\
\hline & & & & Mojo \\
\hline & & & & uPrint \\
\hline & & & MakerBot & Replicator \\
\hline & & & RepRap & RepRap \\
\hline & & & Delta Micro Factory Corporation & UP \\
\hline & & & Beijing Tiertime & Inspire A450 \\
\hline & & Waxes & Essential Dynamics & Imagine \\
\hline & APF & Thermoplastics & Arburg & Freeformer \\
\hline \multirow[t]{12}{*}{ Powder bed fusion } & \multirow[t]{3}{*}{ SLS } & \multirow[t]{3}{*}{ Thermoplastics } & EOS & EOS P \\
\hline & & & Blueprinter & SHS \\
\hline & & & 3D systems & sPro \\
\hline & \multirow[t]{7}{*}{ SLM } & \multirow[t]{7}{*}{ Metals } & EOS & EOSINT M \\
\hline & & & SLM Solutions & SLM \\
\hline & & & 3Geometry & DSM \\
\hline & & & Concept Laser & LaserCusing \\
\hline & & & 3D Systems & ProX \\
\hline & & & Realizer & SLM \\
\hline & & & Renishaw & AM250 \\
\hline & \multirow[t]{2}{*}{ EBM } & \multirow[t]{2}{*}{ Metals } & Arcam & Arcam A2 \\
\hline & & & Sciaky & $\mathrm{DM}$ \\
\hline \multirow[t]{2}{*}{ Sheet lamination } & \multirow[t]{2}{*}{ LOM } & Paper & Mcor Technologies & Matrix $300+$ \\
\hline & & Thermoplastics & Solido & SD300Pro \\
\hline \multirow[t]{3}{*}{ Directed energy deposition } & \multirow[t]{2}{*}{ LMD / LENS } & \multirow[t]{2}{*}{ Metals } & Optomec & LENS 450 \\
\hline & & & Irepa laser & EasyCLAD \\
\hline & EBAM & Metals & Sciaky & VX-110 \\
\hline
\end{tabular}

address the relationship between manufacturing constraints, customer requirements and design guidelines so that the overall cost including assembly and logistics is minimized [23].

$\mathrm{AM}$ in reference to IPPD has been discussed in literature on a few occasions. Klahn et al. [24] suggested two kinds of design strategies for $\mathrm{AM}$; 'manufacturing-driven design strategy' and 'function-driven design strategy'. The former strategy kept in view the manufacturer's perspective which followed certain design rules to mass customize a part by preserving the conventional design, while the latter strategy envisioned the designer's perspective and improved the function of a product as worked upon by Klahn et al. [25] for a medical device used in shockwave therapy. Rapid prototyping itself is a great example of utilizing AM's process advantages by considering a part which is designed for conventional production. Moreover, manufacturing driven design strategy is largely used to mass customize a product in series production as identified by Berger [26] for additive manufactured dental implants. The strategy is also used in direct production of thermoplastic parts via materials such as composites [27]. A global analysis was also proposed by Ponche et al. [28], as part of the function-driven design strategy, to determine functional volumes and Manufacturing Direction (MD) as per AM capabilities. The authors later used them to optimize the design by determining part orientation, optimizing topology, and manufacturing paths by considering manufacturing constraints and considerations [29]. Boivie et al. [30] also streamlined the production sequence of a hybrid-manufacturing cell by integrating AM with Computer Numeric Control (CNC) milling. Furthermore, D' Antonio et al. [31] analyzed and synthesized product and process data by integrating DfAM with Manufacturing Execution System (MES). An approach was also proposed for the modeling of process chains for AM to support the $\mathrm{CE}$ along with process selection and Design for Manufacturability (DFM) in early design stages [32]. Zaman et al. [33] proposed a generic methodology to suggest appropriate manufacturing technology (additive or traditional) keeping in view the interaction between product and process data. Finally, Yazdi et al. [34] proposed an integrated approach to apply CE perspective to AM technology by using DFM-skin and skeleton for process modeling in early stages of product development cycle and suggesting an interface model to support both the design and manufacturing attributes for a product.

All the literature discussed above focused on the integrated approach with more emphasis on modification of DFM for AM and using a combination of the design criteria (e.g., function, cost and environment) and the DFM/DfAM guidelines for successful generation and utilization of the design requirements and attributes. In case of MPS problem which is also an integral decision-making aspect of DFM itself, a lot of work has been done on traditional domain with researches involving cost per unit property methods [35], material and process selection charts [36], casebased reasoning [37], material selection programs [38], knowledgebased systems [39], AHP [40], Technique of Ranking Preferences by Similarity to Ideal Solution (TOPSIS) [41], and ELECTRE III [42], but very little in the AM area. For example, the AHP was used by Mancanares et al. [43] to select AM processes based on the requirements generated from a part. In addition, an adaptive AHP decision model by Armillotta [44] selected a suitable AM process from a set of alternatives for prototypes made from a selected category such as technical prototype, sand casting, etc. The attributes considered included fast build, good accuracy, and reduced material cost. This also opens a window of 


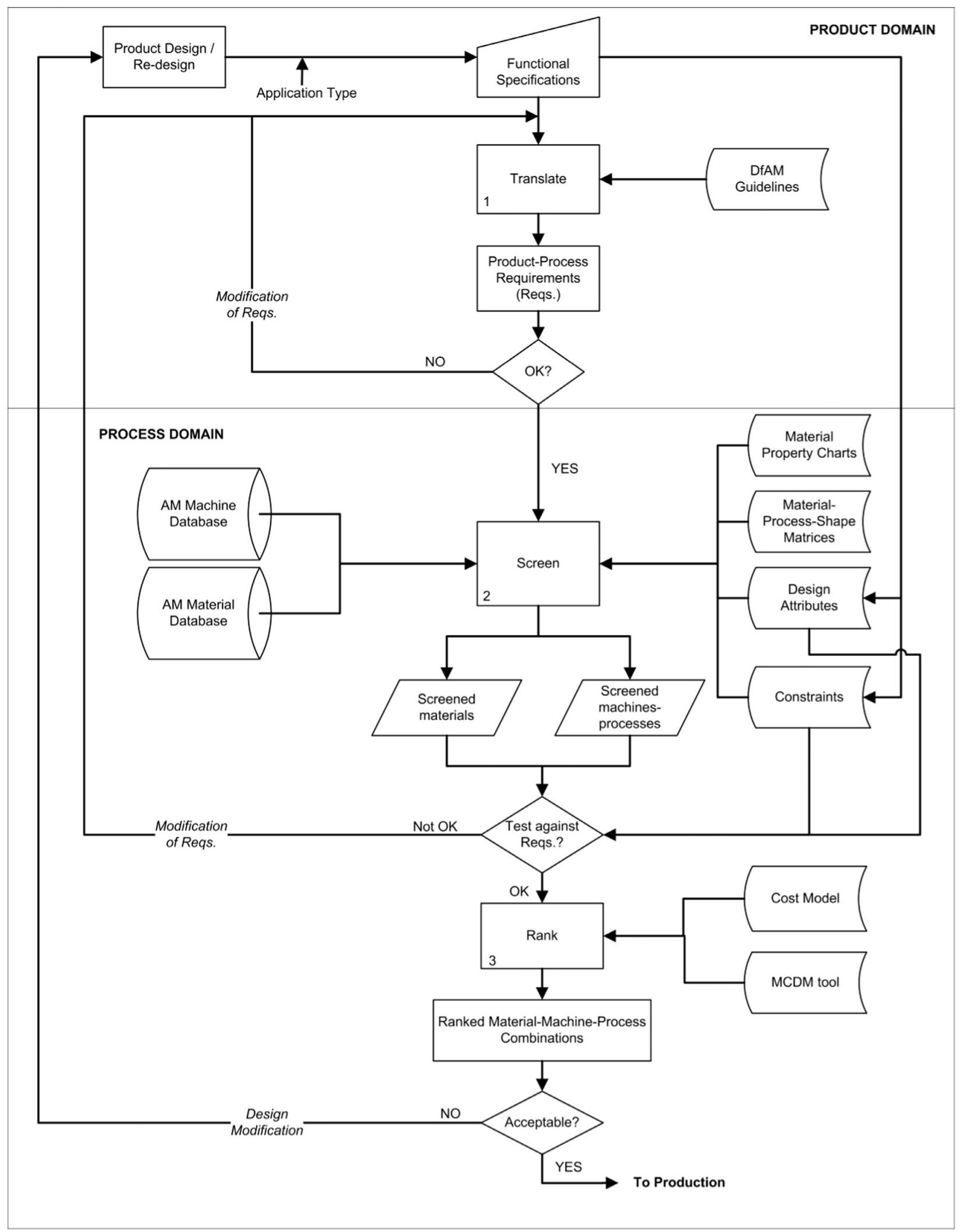

Fig. 1. Proposed MPS Methodology. 


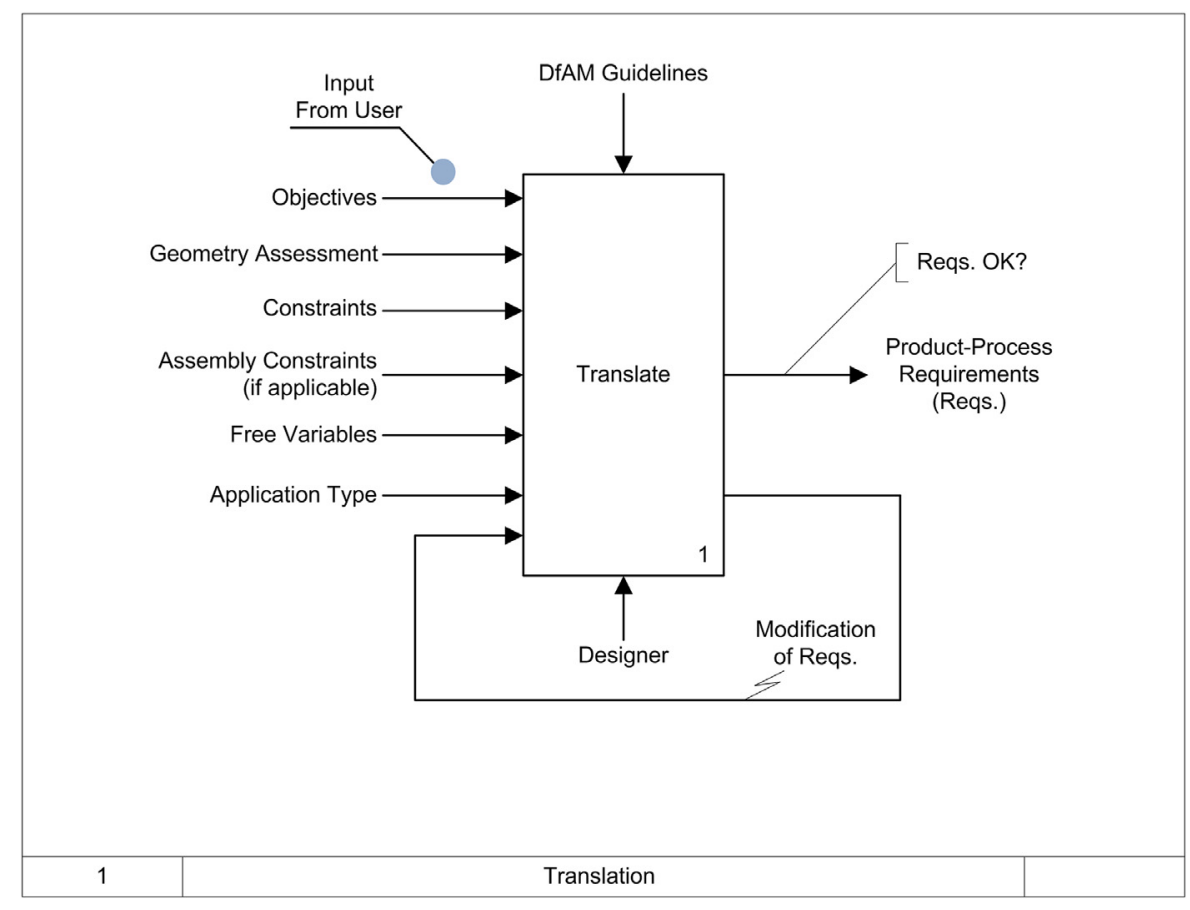

Fig. 2. Translation of product/process requirements.

opportunity to apply AHP for MPS in AM since it is the most widely and successfully used MCDM method. It is evident from literature that AHP has been applied extensively on problems either small-scale or largescale and having multiple criteria. It is suitable for multiple domains, especially manufacturing sector as it relies on the innate human inclination to conduct comparison by catering both subjective and objective attributes [45]. It is applied to material selection in gears [46], selection of non-traditional machining processes, defining weight coefficients for selection of manufacturing processes in conceptual design stage for the body of modular hip joint endoprosthesis [47], and selection of best material for design of lightweight aircraft metallic structures [48].

Therefore, based on the expansive literature reviewed and overarching aim of this research, it has been found that the methods proposed in the literature either focused on the designer's perspective wherein DfAM was catered to address the relationship between product and process data by using the same high level methodology while each phase of DfAM was not clear, or they focused on the manufacturer's perspective which concentrated on the theory of 'pick and choose' with the AHP leading by being the most reliable method. Moreover, the studies were either function-specific or application-specific. It is hence, necessary to simultaneously consider the manufacturing constraints and considerations, customer requirements, the existing pool of available AM materials and the corresponding AM manufacturing processes to optimize design criteria for MPS.

\section{Proposed methodology}

The decision methodology proposed in this paper follows a step by step procedure to attain material-machine combinations for a product under study. The procedure contains three major steps; translation, screening and ranking, and is being dominated globally by DfAM guidelines and the application type. The overall summary of the procedure is shown in Fig. 1.

\subsection{Translation of requirements}

In this step, the designer uses the extracted functional specifications from the CAD model (includes objective, geometry assessment, definition of constraints, identification of free variables and other relevant data) and generates a set of requirements that can be either designrelated, production-related, process-related, or a combination of any of the three, based on the application type and the available DfAM guidelines (see Fig. 2). The methodology has the flexibility to modify design if the requirements generated are not as per the functional specifications. It is however imperative to note here that the process is in early stages of design.

\subsection{Screening of AM materials and manufacturing processes}

Once the requirements are approved, Ashby's charts are used for screening because the objective is assumed to maximize one or few functional requirements. Moreover, a manufacturing task has attributes, such as density, cost, strength, etc., and the objective is to maximize or minimize either or some of them to achieve the functional requirements of the part. These are also referred to as the 'performance indices' like strength-to-weight ratio $\left(\sigma_{f} / \rho\right)$, stiffness-to-weight ratio $(E / \rho)$, etc. Table 14 shows the material indices suggested by Ashby [49] and used in the current study for screening of AM concerned materials and manufacturing processes.

Furthermore, two databases were constructed; each for the materials and machines related to the AM technology. For the AM materials, the database constituted commercially available materials used in various AM machines. The database can be expanded as new materials and

Table 2

Characteristics for material database (developed by authors).

\begin{tabular}{|c|c|c|}
\hline Characteristics & Unit & Description \\
\hline Material & - & Type of material used in AM machine \\
\hline Process & - & $\begin{array}{l}\text { Type of AM process (refer to Table } 1 \text { for } \\
\text { details) }\end{array}$ \\
\hline Machine & - & Type of AM machine as per AM process \\
\hline Yield strength & MPa & Stress endured before plastic deformation \\
\hline Tensile strength & MPa & Resistance of material to break under load \\
\hline Ductility at break & $\%$ & Amount a material stretches before breakage \\
\hline Surface finish & $\mu \mathrm{m}$ & Value of roughness on material \\
\hline Material cost & US\$ & Cost of material \\
\hline Support material cost & US\$ & $\begin{array}{l}\text { Cost of support material used to build support } \\
\text { structure (if required) }\end{array}$ \\
\hline
\end{tabular}


Table 3

AM process and vendors used in the machine database (developed by authors).

\begin{tabular}{|c|c|c|}
\hline Category & AM process & AM manufacturer \\
\hline \multirow[t]{8}{*}{ Personal } & SLA & 3D Systems, DWS Lab \\
\hline & 3DP & Voxeljet, ExOne \\
\hline & DLP & DWS Lab, Rapidshape, MoonRay, Autodesk, B9CreatoR, UNCIA 3D, Kudo 3D, Colido DLP \\
\hline & FDM & 3D Systems, Stratasys, Makerbot, RepRap, Raise3D, TierTime \\
\hline & MJM & Stratasys \\
\hline & LENS & Optomec \\
\hline & LOM & Mcor Technologies, Solido \\
\hline & SLM & Concept Laser, Realizer \\
\hline \multirow[t]{11}{*}{ Professional } & 3DP & Voxeljet, ExOne \\
\hline & SLA & XYZ Printing, Formlabs, DWS Lab \\
\hline & CJP & 3D Systems \\
\hline & DLP & Rapidshape, Morpheus \\
\hline & FDM & Stratasys, Makerbot, Raise3D, TierTime, Essential Dynamics \\
\hline & MJM & 3D Systems, Solidscape, Stratasys \\
\hline & SAS & Asiga \\
\hline & LENS & Optomec \\
\hline & LOM & Mcor Technologies, Solido \\
\hline & SLM & EOS, SLM Solutions, Concept Laser, Realizer, Renishaw, 3Geometry \\
\hline & SLS & EOS, Blueprinter \\
\hline \multirow[t]{12}{*}{ Production } & 3DP & Voxeljet, ExOne \\
\hline & SLA & 3D Systems, Lithoz \\
\hline & DLP & EnvisionTEC, Rapidshape \\
\hline & FDM & Stratasys, DeltaWasp, TierTime \\
\hline & MJM & Stratasys \\
\hline & DMP & 3D Systems \\
\hline & SLM & SLM Solutions, Concept Laser, Renishaw, EOS, 3Geometry \\
\hline & SLS & 3D Systems, EOS \\
\hline & EBM & Arcam \\
\hline & EBAM & Sciaky \\
\hline & LENS & Optomec \\
\hline & LMD & BeAM \\
\hline
\end{tabular}

Table 4

Characteristics for machine database (developed by authors).

\begin{tabular}{lll}
\hline Characteristics & Unit & Description \\
\hline Category & - & Type of category the machine belongs to (personal, professional, production) \\
Manufacturer & - & Name of manufacturer \\
Machine & - & Name of AM machine \\
AM pprocess & - & Type of AM process \\
Build materials & - & Type of materials used to build a part \\
Support materials & - & Type of materials used for support structure (if required) \\
Applications & - & Areas of application for the AM machine \\
Layer thickness & $\mu \mathrm{m}$ & Minimum layer thickness achieved during part build \\
Accuracy & $\mathrm{mm}$ & Minimum deviation in part dimension from original on successive builds \\
Build volume & $\mathrm{mm}{ }^{3}$ & Total volume of space available for part build in a machine \\
Printing Speed & $\mathrm{mm} / \mathrm{h}$ & Average speed to build a part with dimensions $(50 \times 50 \times 20)$ mm ${ }^{3}$ \\
Volume build rate & $1 / \mathrm{h}$ or $\mathrm{kg} / \mathrm{h}$ & Amount of material deposited by a machine per hour \\
Machine Cost & $\mathrm{US} \$$ & Cost of AM machine \\
Post-processing & Yes/No & Indicator to identify if post-processing is required for a manufactured part \\
\hline
\end{tabular}

production technologies of AM are added with the passage of time. The characteristics for the materials used in the repository are included in Table 2. The database might not be exhaustive, but it can provide a comprehensive outlook on majority of the materials used in AM machines today.

Similarly, the machine database provided data for 134 AM machines available commercially today. The whole lot was divided into three groups; personal, professional and production. The classification was inspired both from literature as well as the division already being used by the three leading AM technology vendors, i.e., 3D Systems, Stratasys and EOS GmbH. As far as the classification from vendors is concerned, it targets the area of application where the machine is being used, as well as the size of the part being built. The scan speed, build chamber size, minimum layer thickness, machine cost, etc., are the factors that both the vendors and the authors used to categorize the machines in the database. On the front of literature, Mancanares et al. [43] used the same classification to select AM processes based on parts selection cri- teria. They used a limited 45 different machines from the top 3 vendors of AM technology. Furthermore, a near classification can also be witnessed in a research report published by Bechthold et al. [50]. 'Personal' machines included the ones that can be used for personal/desktop use as well as on the lower step of industrial printers for business. 'Professional' machines generally comprised of purposes such as prototyping before full-scale production and required a certain skill set. Such machines require an open space such as an office with a good ventilation. Lastly, the 'Production' machines utilized high level of automation and control of processes to not only print prototypes but also final consumer products. These machines required a shop floor environment along with a dedicated operator. Table 3 shows the AM processes and manufacturers listed in the database. Moreover, the characteristics of AM machines used in the database are listed in Table 4.

The complete data flow for the screening phase are shown in Figs. 3 and 4 showing screening of AM materials and AM machines, respectively: 


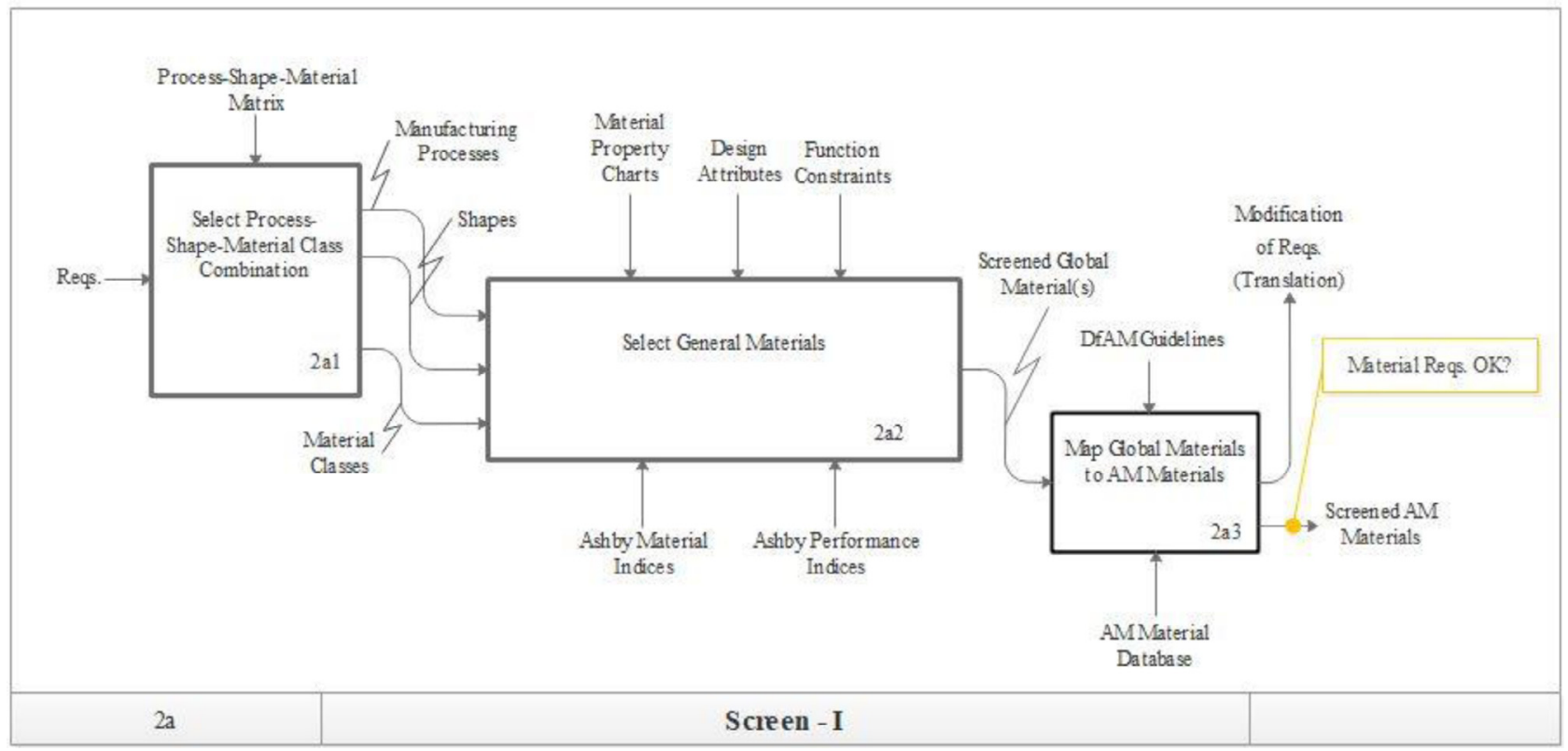

Fig. 3. Screening of AM materials - I.

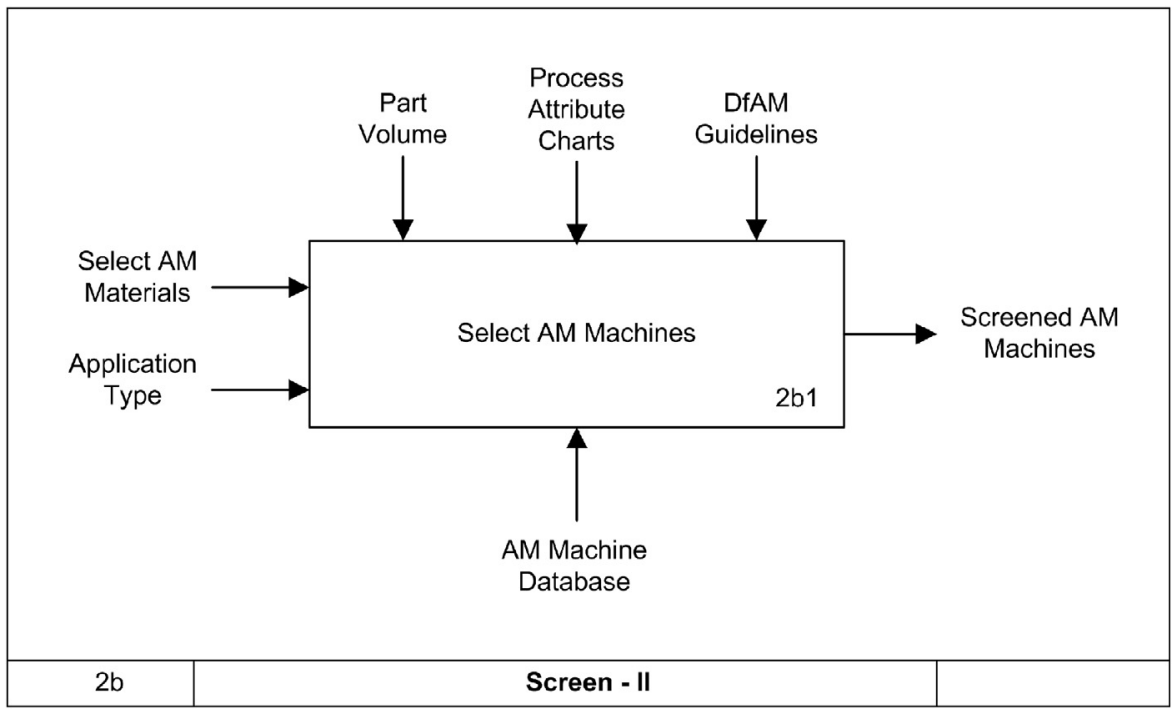

Fig. 4. Screening of AM materials - II.

\subsection{Ranking of AM materials and manufacturing processes}

The ranking of materials and manufacturing processes/machines for the AM technology was validated by (1) Classical AHP, which was utilized because all the attributes were assumed to be independent, and (2) cost model adopted by Yim and Rosen [51]. Each of the two subprocesses are explained in the text to follow.

\subsection{1. $A H P$}

The classical AHP has the overall objective or goal at the top level, criteria and sub-criteria at the middle level and various alternatives at the lowest level. The data in each level is tabulated in a square matrix whose diagonal elements are 1 and the $(j, i)$ element of the matrix is the reciprocal of the $(i, j)$ element. Here $i$ is the row index and $j$ is the column index. A scale is used to do the pair-wise comparison of the same hierarchy elements in each level which is listed in Table 5 [52].

The working procedure of AHP for MPS of AM technology is given in Fig. 5. Each of the design criteria - function, cost and environment - were split into machine and material-related parameters to decompose the problem for viable pair-wise individual comparisons at material and machine level. The material parameters/attributes included material strength properties, surface finish, material cost, material usage efficiency, environmental impact, and landfill waste. In addition, the machine parameters/attributes included geometry complexity, accuracy, minimum layer thickness, build volume, machine cost, labor cost, and build speed. The parameters provided a healthy blend of product and process attributes for a good compromise of MPS for AM technology.

Table 5

Relative scale of criterion [52].

\begin{tabular}{lll}
\hline Scale & Numeric assessment & Reciprocal \\
\hline Extremely preferred & 9 & $1 / 9$ \\
Very, very strong & 8 & $1 / 8$ \\
Very strong & 7 & $1 / 7$ \\
Strong plus & 6 & $1 / 6$ \\
Strongly preferred & 5 & $1 / 5$ \\
Moderate plus & 4 & $1 / 4$ \\
Moderately preferred & 3 & $1 / 3$ \\
Weak plus & 2 & $1 / 2$ \\
Equally preferred & 1 & 1 \\
\hline
\end{tabular}




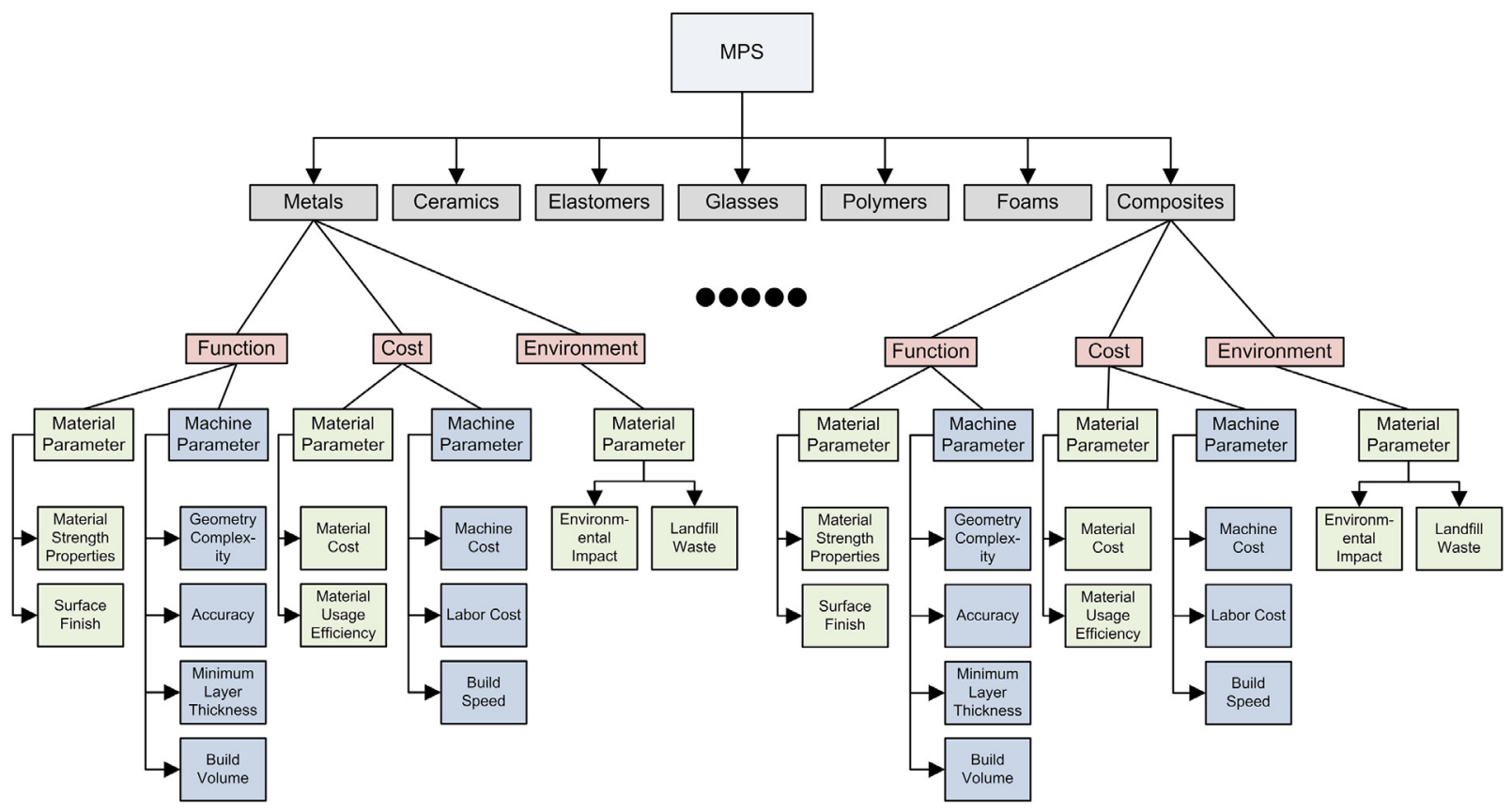

Fig. 5. AHP Decision Structure.

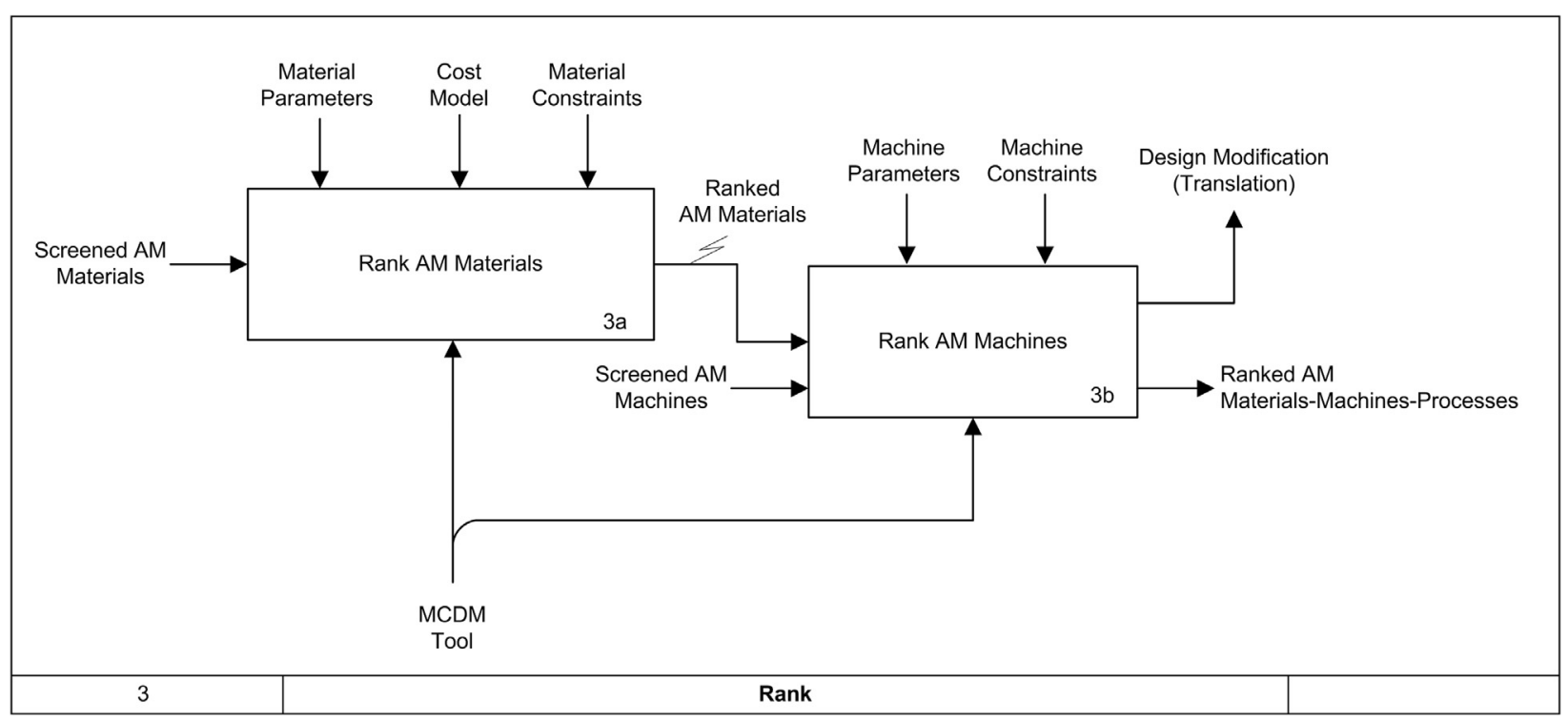

Fig. 6. Ranking of AM materials and machines-processes.

Moreover, subjective and objective weights are included for all areas of application. The subjective weights were utilized when the application areas and the design criteria were considered collectively, and objective weights were assigned to each of the sub-criteria to rate their level of importance in the overall analysis.

\subsubsection{Cost model for overall material cost}

The cost model adopted by Yim and Rosen [51] was chosen for finding the overall material cost for an AM material. As per the literature reviewed, the selected cost model was applicable on a wide range of AM processes in early stages of design. The cost model is given in Eq. (1):

$M=K_{s} \times K_{r} \times N \times v \times C_{m} \times \rho$

where, $M=$ overall material cost (US $\$$ ), $K_{s}=$ support structure factor, $K_{r}=$ recycling factor, $N=$ number of parts, $v=$ part volume $\left(\mathrm{mm}^{3}\right)$, $C_{m}=$ material rate per unit weight (US\$ $/ \mathrm{kg}$ ) and $\rho=$ material density $\left(\mathrm{kg} / \mathrm{mm}^{3}\right) . K_{s}$ is used to capture cost of additional material usage for building support structures and is usually in the range of $1.1-1.5$ while $K_{r}$ is used to find the cost contribution of wasting loose powder which is not recycled after the build. $K_{r}$ usually lies in the range of $1-7$.

The result of 'ranking' is a compromised yet acceptable set of AM materials and manufacturing machines for a derived AM manufacturing process. The complete information and data flow for the ranking of AM materials and machines-processes is given in Fig. 6.

\section{Industrial case study}

\subsection{Problem definition}

The industrial case study is based on a 'drilling grid' used in an aerospace industry to drill holes with precision and accuracy on the sides of the aircraft body. As a conventional industrial practice, drilling 


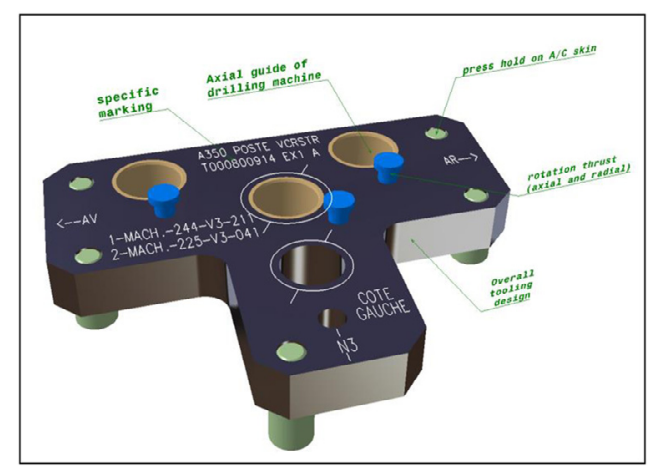

Fig. 7. Drilling Grid.

Table 6

Functional specifications for Drilling Grid.

\begin{tabular}{ll}
\hline Factor & Description \\
\hline Objective & Maximize strength \\
Constraints & The length of the holes should be $20 \mathrm{~mm}(\mathrm{~mm})$ \\
For locking screws, the part shall withstand
\end{tabular}

grids are manufactured with aluminum alloys using traditional material removal processes, such as conventional machining. Furthermore, twenty-four hours' time margin is available for the design, validation and delivery of the grids in the aerospace industry, but this deadline is usually not followed. Missing drilling grids can occur due to late definition / modification of design; impossible repairing after defective status is flagged and fatigue impact on quality. Also, grids can reach up to $50 \mathrm{~kg}$ when handled by one operator in worst ergonomic conditions such as under the aircraft fuselage. Moreover, since the part is not big, manufacturing within the aircraft body will save time, cost and logistics. Therefore, the objective of the study is to assess the best compromise of AM materials and processes for building the drilling grid that can fulfill the functional requirements and time constraints. The drilling grid is shown in Fig. 7.

\subsection{MPS data collection}

The purpose of this phase was to conduct a brainstorming session with the concerned experts in the aerospace industry. A generic question and answer session was designed with the purpose of gathering data for the translation of functional specifications by the authors of this manuscript. Questions were e-mailed to the selected experts before the actual interviews. Face-to-face interviews were then conducted. This technique of data collection was chosen so that the preference and views of the interviewees could be accounted for. As an example, the experts preferred non-metallic material for the manufacture of the part. Moreover, the experts participated voluntarily in this research. The functional specifications generated are listed in Table 6 .

\subsection{Screening of AM materials and machines}

Ashby's charts and material indices related to maximizing strength and stiffness were used to screen the first global set of materials based on the generated functional specifications. Since, the drilling grid can be interpreted as a 'beam', three material indices were used as guidelines of minimum mass and cost on Ashby's charts (See Table 14):

$\frac{E^{1 / 2}}{\rho}$

$\frac{\sigma_{y}^{2 / 3}}{\rho}$

$\frac{\sigma_{y}^{2 / 3}}{C_{m} \rho}$

where $\rho$ =density, $\mathrm{E}=$ Young's modulus, $\sigma_{\mathrm{y}}=$ Elastic limit and $\mathrm{C}_{\mathrm{m}}=$ cost $/ \mathrm{kg}$.

The global set of materials included Acrylonitrile Butadiene Styrene (ABS)-, Polypropylene (PP)-, and Polycarbonate (PC)-related materials. Each of the global materials were then used to find the associated materials in the materials' database for different AM processes. Similarly, considering the area of application, i.e. aerospace, the relevant machines were also screened from the machines' database. Few more materials such as 'Nylon' were added to the final list as they displayed the functional specifications generated earlier for the drilling grid. The final set of screened AM materials, processes and machines are listed in Table 7.

\subsection{Ranking of AM materials and machines}

To facilitate the pairwise comparisons by AHP, the materials listed in Table 7 were grouped as per the 'base material'. For example, all materials either showing properties of $A B S$ or looked like $A B S$ were separated and grouped under ABS such as ABS-M30, ABS-ESD7, ABSi, ABS-M30i, PCABS, ABS Plus, VisiJet M3-X, VisiJet M5-X, VisiJet CR-WT, DIGITAL ABS, ABStuff and Plas. The same procedure was followed for PC and PP related materials. The materials left after this grouping were collected in another set. The AHP was conducted as explained previously in Section 3.3.1 and Fig. 5. As the concerned AM processes (as per Table 7) included MJM, SAS, DLP and FDM, the cost parameters for each process are listed in Table 8.

For the case of ABS-related materials and material attribute 'material strength properties', Table 9 shows one of the several decision matrices used for comparison. The results from all material comparisons from each set are listed in Table 10.

As per the results displayed in Table 10, DIGITAL ABS, RGD 450, PC, PC ISO, Nylon 6, RGD 875 and ULTEM 1010 were selected. These materials were matched with the screened machines in Table 7 to generate Fortus $250 \mathrm{mc}$, Fortus $380 \mathrm{mc} / 450 \mathrm{mc}$, Fortus $900 \mathrm{mc}$ and Objet 1000 Plus machines for the AHP's pair-wise comparisons. The result for machine comparison is given in Table 11 .

Consequently, the final MPS for the drilling grid included AM machine 'Fortus 900 mc' running on AM Process 'FDM' and can use any of Nylon 6, ULTEM 1010, PC and PC ISO as the AM build materials. The final set of materials proved to be a good compromise for building the drilling grid.

\section{Comparative analysis and validation}

To compare and validate the proposed method in Section 3, the same case study (drilling grid) was used and applied on another pop- 
Table 7

Screened set of AM materials, processes and machines.

\begin{tabular}{|c|c|c|c|}
\hline Manufacturer & Machine & $\mathrm{AM}$ process & Materials \\
\hline \multirow[t]{9}{*}{ 3D systems } & \multirow[t]{3}{*}{ ProJet MJP 2500 series } & \multirow[t]{3}{*}{ MJM } & VisiJet M2 RBK \\
\hline & & & VisiJet M2 RCL \\
\hline & & & VisiJet M2 RWT \\
\hline & ProJet $3510 / 3500 / 3600$ & MJM & VisiJet M3-X \\
\hline & \multirow[t]{3}{*}{ ProJet 5000} & \multirow[t]{3}{*}{ MJM } & VisiJet M5 Black \\
\hline & & & VisiJet M5 MX \\
\hline & & & VisiJet M5-X \\
\hline & \multirow[t]{2}{*}{ ProJet MJP 5500X } & \multirow[t]{2}{*}{ MJM } & VisiJet CR-CL \\
\hline & & & VisiJet CR-WT \\
\hline Asiga & PICO2 / Freeform PRO2 & SAS & Plas \\
\hline \multirow[t]{8}{*}{ EnvisionTEC } & \multirow[t]{2}{*}{ P4 MINI XL } & \multirow[t]{2}{*}{ DLP } & RC31 \\
\hline & & & RC90 \\
\hline & \multirow[t]{6}{*}{ P4 Standard XL } & \multirow[t]{6}{*}{ DLP } & R11 \\
\hline & & & RCP 30 \\
\hline & & & R5 Grey \\
\hline & & & RC31 \\
\hline & & & ABflex \\
\hline & & & ABStuff \\
\hline \multirow[t]{17}{*}{ Stratasys } & \multirow{14}{*}{ Fortus $380 \mathrm{mc} 450 \mathrm{mc} / 250 \mathrm{mc} / 900 \mathrm{mc}$} & \multirow[t]{14}{*}{ FDM } & ABS plus $(250 \mathrm{mc})$ \\
\hline & & & ABSi $(900 \mathrm{mc})$ \\
\hline & & & ABS-M30 (380/450 mc, $900 \mathrm{mc})$ \\
\hline & & & ABS-M30i $(380 / 450 \mathrm{mc}, 900 \mathrm{mc})$ \\
\hline & & & ABS ES-D7 $(380 / 450 \mathrm{mc}, 900 \mathrm{mc})$ \\
\hline & & & ASA $(380 / 450 \mathrm{mc})$ \\
\hline & & & Nylon $6(900 \mathrm{mc})$ \\
\hline & & & Nylon $12(380 / 450 \mathrm{mc}, 900 \mathrm{mc})$ \\
\hline & & & PC $(380 / 450 \mathrm{mc}, 900 \mathrm{mc})$ \\
\hline & & & PCABS(900 mc) \\
\hline & & & PC ISO $(380 / 450 \mathrm{mc}, 900 \mathrm{mc})$ \\
\hline & & & PPSF/PPSU (900 mc) \\
\hline & & & ULTEM 1010 (380/450 mc) \\
\hline & & & ULTEM 9085(380/450 mc, $900 \mathrm{mc})$ \\
\hline & \multirow{3}{*}{ Objet 1000 Plus } & \multirow[t]{3}{*}{ MJM } & Rigur (RGD 450, 430) \\
\hline & & & Vero Family (RGD 835, 850, 840, 875) \\
\hline & & & DIGITAL ABS Ivory/ABS2 Ivory \\
\hline
\end{tabular}

Table 8

Cost model parameters for Drilling Grid.

\begin{tabular}{lllll}
\hline Parameters & MJM & SAS & DLP & FDM \\
\hline $\mathrm{C}_{\mathrm{m}}(\mathrm{US} \$ / \mathrm{kg})^{*}$ & 340.9 & 450 & 339.2 & 339 \\
$\mathrm{~K}_{\mathrm{s}}$ & 1.1 & 1.1 & 1.3 & 1.3 \\
$\mathrm{~K}_{\mathrm{r}}$ & 1.0 & 1.0 & 1.0 & 1.0 \\
$\mathrm{~N}$ & 1 & 1 & 1 & 1 \\
$\mathrm{v}\left(\mathrm{mm}^{3}\right)$ & 46,000 & 46,000 & 46,000 & 46,000 \\
\hline
\end{tabular}

* average material rate per unit weight.

ular MCDM method for material and process selection; Simple Additive Weighting (SAW). SAW is a simple yet effective method based on weighted average using arithmetic mean. Since, it is a proportional linear transformation of the raw data, the relative order of the magnitude of the standardized scores remains equal [53].
Each of the criteria; function, cost and environment, were assigned weights of $77.2 \%, 17.3 \%$ and $5.5 \%$, respectively, considering the emphasis of the experts on part functionality. Each of the attributes were further assigned individual weightages with respect to materials and machines, normalized decision matrices were constructed, and the scores were calculated for each alternative. For the sake of simplicity, only the results were displayed. Moreover, the same materials as suggested in Table 7 were chosen for the application of SAW. Table 12 shows the final ranked results along with their comparison with the final results generated by AHP.

It is evident from the results that the validation of the proposed methodology via SAW helped to generate not only the same set of materials as AHP but also helped to explore three more materials; VisiJet M3-X, RGD 430 and PPSF/PPSU. The generated materials were then matched with the screened machines in Table 7 to generate ProJet 3510/3500/3600, Fortus $250 \mathrm{mc}$, Fortus $380 \mathrm{mc} / 450 \mathrm{mc}$, Fortus

Table 9

Decision matrix of the AHP for material attribute 'material strength properties' (ABS-related).

\begin{tabular}{|c|c|c|c|c|c|c|c|c|c|c|c|c|}
\hline & ABS-M30 & ABS-ESD7 & $\mathrm{ABSi}$ & ABS-M30i & PCABS & ABS Plus & VisiJet M3-X & VisiJet M5-X & VisiJet CR-WT & DIGITAL ABS & ABStuff & Plas \\
\hline ABS-M30 & 1 & 2 & 3 & 3 & $1 / 3$ & 1 & $1 / 5$ & $1 / 4$ & $1 / 5$ & $1 / 6$ & $1 / 3$ & $1 / 2$ \\
\hline ABS-ESD7 & $1 / 2$ & 1 & 2 & 1 & $1 / 3$ & 2 & $1 / 3$ & $1 / 3$ & $1 / 4$ & $1 / 6$ & $1 / 3$ & $1 / 3$ \\
\hline $\mathrm{ABSi}$ & $1 / 3$ & $1 / 2$ & 1 & 1 & $1 / 2$ & $1 / 2$ & $1 / 5$ & $1 / 2$ & $1 / 3$ & $1 / 6$ & $1 / 4$ & $1 / 4$ \\
\hline ABS-M30i & $1 / 3$ & 1 & 1 & 1 & 1 & $1 / 2$ & $1 / 3$ & $1 / 2$ & $1 / 5$ & $1 / 6$ & $1 / 3$ & $1 / 3$ \\
\hline PCABS & 3 & 3 & 2 & 1 & 1 & 3 & $1 / 3$ & 2 & $1 / 2$ & $1 / 6$ & $1 / 4$ & $1 / 2$ \\
\hline ABS Plus & 1 & $1 / 2$ & 2 & 2 & $1 / 3$ & 1 & $1 / 2$ & $1 / 2$ & $1 / 3$ & $1 / 5$ & 1 & $1 / 2$ \\
\hline VisiJet M3-X & 5 & 3 & 5 & 3 & 3 & 2 & 1 & 4 & 4 & 2 & 2 & 3 \\
\hline VisiJet M5-X & 4 & 3 & 2 & 2 & $1 / 2$ & 2 & $1 / 4$ & 1 & 3 & $1 / 5$ & 2 & 2 \\
\hline VisiJet CR-WT & 5 & 4 & 3 & 5 & 2 & 3 & $1 / 4$ & $1 / 3$ & 1 & $1 / 5$ & $1 / 3$ & 1 \\
\hline DIGITAL ABS & 6 & 6 & 6 & 6 & 6 & 5 & $1 / 2$ & 5 & 5 & 1 & 3 & 4 \\
\hline ABStuff & 3 & 3 & 4 & 3 & 4 & 1 & $1 / 2$ & $1 / 2$ & 3 & $1 / 3$ & 1 & 1 \\
\hline Plas & 2 & 3 & 4 & 3 & 2 & 2 & $1 / 3$ & $1 / 2$ & 1 & $1 / 4$ & 1 & 1 \\
\hline
\end{tabular}


Table 10

Results of the AHP for material comparisons.

\begin{tabular}{llllll}
\hline Rank & ABS-related & PP-related & PC-related & Nylon-related & Remaining \\
\hline$\# 1$ & DIGITAL ABS & RGD 450 & PC & Nylon 6 & RGD 875 \\
$\# 2$ & VisiJet M3-X & RGD 430 & PC ISO & Nylon 12 & ULTEM 1010 \\
$\# 3$ & & VisiJet M5 Black & VisiJet M2 RCL & - & ULTEM 9085 \\
$\# 4$ & VisiJet M5-X & VisiJet M5-X & VisiJet CR-CL & - & R5 Grey \\
$\# 5$ & VisiJet CR-WT & - & - & - & R 11 \\
$\# 6$ & Plas & - & - & - & PPSF \\
$\# 7$ & ABS Plus & - & - & - & RCP 30 \\
$\# 8$ & ABS-M30 & - & - & - & VisiJet M2 RWT \\
$\# 9$ & ABS-ESD7 & - & - & - & RC 90 \\
$\# 10$ & ABS-M30i & - & - & - & VisiJet M5 MX \\
$\# 11$ & ABSi & - & - & - & VisiJet M2 RBK \\
$\# 12$ & - & - & - & ASA \\
\hline
\end{tabular}

Table 11

Decision hierarchy for final selection of AM machines (Drilling Grid).

\begin{tabular}{llllll}
\hline Parameter & Global priorities (\%) & Fortus $250 \mathrm{mc}$ & Fortus $380 \mathrm{mc} / 450 \mathrm{mc}$ & Fortus $900 \mathrm{mc}$ & Objet 1000 Plus \\
\hline Geometry complexity & 11.7 & 0.029 & 0.029 & 0.029 & 0.029 \\
Minimum layer thickness & 14.7 & 0.013 & 0.023 & 0.013 & 0.100 \\
Accuracy & 20.2 & 0.023 & 0.063 & 0.102 & 0.014 \\
Build volume & 12.1 & 0.009 & 0.013 & 0.061 & 0.039 \\
Build speed & 26.9 & 0.026 & 0.113 & 0.113 & 0.017 \\
Machine cost & 7.9 & 0.038 & 0.023 & 0.009 & 0.009 \\
Labor cost & 6.5 & 0.016 & 0.016 & 0.016 & 0.016 \\
& 100 & $15.4 \%$ & $28.0 \%$ & $34.3 \%$ & $22.4 \%$ \\
\hline
\end{tabular}

Table 12

Ranked materials' comparison for AHP and SAW.

\begin{tabular}{lllll}
\hline Rank & Materials AHP & Score & Materials SAW & Score \\
\hline$\# 1$ & Digital ABS & 0.203 & ULTEM 1010 & 0.148 \\
$\# 2$ & ULTEM 1010 & 0.18 & DIGITAL ABS & 0.146 \\
$\# 3$ & RGD 875 & 0.167 & RGD 875 & 0.136 \\
$\# 4$ & Nylon 6 & 0.153 & Nylon 6 & 0.119 \\
$\# 5$ & RGD450 & 0.113 & VisiJet M3-X & 0.097 \\
$\# 6$ & PC & 0.094 & RGD 450 & 0.084 \\
$\# 7$ & PCISO & 0.09 & RGD 430 & 0.077 \\
$\# 8$ & - & - & PPSF/PPSU & 0.066 \\
$\# 9$ & - & - & PCISO & 0.065 \\
$\# 10$ & - & - & PC & 0.062 \\
\hline
\end{tabular}

Table 13

Ranked machines' scoring with SAW.

\begin{tabular}{lll}
\hline Rank & Machine & Score \\
\hline$\# 1$ & Fortus $900 \mathrm{mc}$ & 0.25 \\
$\# 2$ & Projet $3510 / 3500 / 3600$ & 0.23 \\
$\# 3$ & Fortus $380 \mathrm{mc} / 450 \mathrm{mc}$ & 0.20 \\
$\# 4$ & Objet $1000 \mathrm{Plus}$ & 0.17 \\
$\# 5$ & Fortus $250 \mathrm{mc}$ & 0.16 \\
\hline
\end{tabular}

Table 14

Material indices suggested by Ashby [49].

\begin{tabular}{ll}
\hline Material indices & \\
Function, objective and constraints & Index \\
\hline Tie, minimum weight, stiffness prescribed & $\frac{E}{\rho}$ \\
Beam, minimum weight, stiffness prescribed & $\frac{E^{1 / 2}}{\rho^{2 / 3}}$ \\
Beam, minimum weight, strength prescribed & $\frac{\sigma_{y}^{\rho / 3}}{\rho}$ \\
Beam, minimum cost, stiffness prescribed & $\frac{E^{1 / 2}}{C_{m p}}$ \\
Beam, minimum cost, strength prescribed & $\frac{\sigma_{y}^{2 / 3}}{C_{m p}}$ \\
Column, minimum cost, buckling load prescribed & $\frac{E^{1 / 2}}{C_{m} \rho}$ \\
Spring, minimum weight for given energy storage & $\frac{\sigma_{y}^{2}}{E_{\rho}}$ \\
Thermal insulation, minimum cost, heat flux prescribed & $\frac{1}{C_{c} \rho}$ \\
Electromagnet, maximum field, temperature rise prescribed & $\frac{C_{p} \rho}{\rho_{e}}$ \\
\hline
\end{tabular}

$\rho=$ Density, $\mathrm{E}=$ Young's modulus, $\sigma \mathrm{y}=$ elastic limit, $C_{m}=$ cost $/ \mathrm{kg}, \lambda=$ thermal conductiv-

ity, $\rho e=$ electrical resistivity, $\mathrm{Cp}=$ specific heat
$900 \mathrm{mc}$ and Objet 1000 Plus machines for the SAW scoring. The machines ranked as per the obtained scores are listed in Table 13.

Similarly, the final MPS for the drilling grid included AM machine 'Fortus 900 mc' running on AM Process 'FDM' and can use any of Nylon 6, ULTEM 1010, PC, PPSF/PPSU and PC ISO as the AM build materials.

\section{Conclusion and discussion}

IPPD is a collaborative product development effort which takes inspiration from CE and provides output in the form of reduced costs, increased functional performance, and sustainability. A generic decision methodology, based on Ashby's material selection charts and MCDM, is presented in this paper to suggest the best compromise of material(s), manufacturing process(es) and machine(s) for AM technology. Apart from providing the aerospace industry with a convincing solution, the proposed methodology can also be used easily as a guideline for researchers in the field of IPPD to provide first-hand information related to AM MPS for all areas of application. When the results were discussed with the concerned experts in the aerospace industry, they confirmed them.

Furthermore, the methodology used screening and ranking procedures to select the best compromise of AM materials, manufacturing processes and machines by considering both the subjective and objective weights. The subjective weights were used when the areas of application along with the design criteria were considered while objective weights were associated to each of the sub-criteria. The objective weights were application-area specific and were being governed by the assigned global priorities. The study was an intensive design task which can be applied on all areas of application to facilitate the designers. It employed step by step and easy to implement procedures in conjunction with the DfAM guidelines, application type, functional constraints, and part requirements to generate material and machine combinations for a given AM manufacturing process(es) using two different MCDM methods; AHP and SAW. Both methods helped validate the proposed methodology. Moreover, the scope of the methodology doesn't end here as it can be expanded to include multiple design criteria with both dependent and independent design attributes. The splitting of parameters into two groups, i.e. machine-related and material-related, also provided an in-depth opportunity to study each parameter in detail with respect 
to its associated design criteria. Finally, the generated AM materials and machines with respect to the chosen AM process provided sufficient opportunity for the consumer to try multiple combinations as per constraining factors such as budget.

To summarize, AM not only has the potential to build anything, but also carries the capability to implement it as well. Therefore, it has become essential to simultaneously address both the product and process data for effective MPS - keeping in view various design criteria, attributes, functionality constraints and areas of application - to act truly as a disruptive technology for both the consumer and manufacturer.

\section{Supplementary materials}

Supplementary material associated with this article can be found, in the online version, at doi:10.1016/j.rcim.2017.12.005.

\section{References}

[1] Wohlers T. Wohlers report 2016: Global Reports, Wohlers Associates, 2016 Belgium.

[2] B. Ahuja, M. Karg, M. Schmidt, Additive manufacturing in production: challenges and opportunities, SPIE LASE, International Society for Optics and Photonics, 2015, doi:10.1117/12.2082521

[3] D.E. Whitney, Manufacturing by design, Harv. Bus. Rev. 66 (4) (1988) 83-91.

[4] Le V.T., Paris H., Mandil G. Using additive and subtractive manufacturing technologies in a new re-manufacturing strategy to produce new parts from end-of-life parts. 22 ème Congrès Français de Mécanique 2015, Lyon, France.

[5] V. Alfieri, P. Argenio, F. Caiazzo, V. Sergi, Reduction of surface roughness by means of laser processing over additive manufacturing metal parts, Materials (2017), doi:10.3390/ma10010030.

[6] S. Tichkiewitch, M. Veron, Methodology and product model for integrated design using a multi-view system, CIRP Annals - Manuf. Technol. 46 (1) (1997) 81-84.

[7] C. Loch, C. Terwiesch, Product development and concurrent engineering, Encyclopedia Prod. Manuf. Manage. 16 (2000) 567-575.

[8] A. Hassan, A. Siadat, J.Y. Dantan, P. Martin, Conceptual process planning - an improvement approach using QFD, FMEA, and ABC methods, Rob. Comput. Integr. Manuf. 26 (4) (2010) 392-401.

[9] D.W. Rosen, Computer-aided design for additive manufacturing of cellular structures, Comput. Aided Design Appl. 4 (5) (2007) 585-594.

[10] B. Vayre, F. Vignat, F. Villeneuve, Metallic additive manufacturing: state-of-the-art review and prospects, J. Mech. Ind. 13 (2012) 89-96.

[11] R. Hague, S. Mansour, N. Saleh, Design opportunities with rapid manufacturing, J, Assembly Autom. 23 (4) (2003) 346-356.

[12] N. Hopkinson, P. Dickens, Emerging rapid manufacturing processes, in: Rapid Manufacturing-An Industrial Revolution for the Digital Age, John Wiley, Chichester, 2006, pp. $55-80$.

[13] T.C. Kuo, S.H. Huang, H.C. Zhang, Design for manufacture and design for ' $x$ ': concepts, applications and perspectives, J. Comput. Ind. Eng. 41 (2001) 241-260.

[14] M. Cotteleer, J. Holdowsky, M. Mahto, The 3D opportunity primer: the basics of additive manufacturing, A Deloitte Series On Additive Manufacturing, Deloitte University Press, 2013.

[15] F. Sharon, Additive manufacturing technology: potential implications for U.S. manufacturing competitiveness, J. Int. Commerce Econ. 6 (1) (2014) 41-74.

[16] R.E. Giachetti, A decision support system for material and manufacturing process selection, J. Intell. Manuf. 9 (1997) 265-276.

[17] M.K. Thompson, G. Moroni, T. Vaneker, G. Fadel, R.I. Campbell, I. Gibson, A. Bernard, J. Schulz, P. Graf, B. Ahuja, F. Martina, Design for additive manufacturing: trends, opportunities, considerations and constraints, CIRP Annals - Manuf. Technol. 65 (2016) 737-760.

[18] ASTM, Standard terminology for additive manufacturing technologies, Standard F2792-12a, ASTM International, 2012 www.astm.org, doi:10.1520/F2792-10.

[19] M.D. Monzon, Z. Ortega, A. Martinez, F. Ortega, Standardization in additive manufacturing: activities carried out by international organizations and projects, Int. J. Adv. Manuf. Technol. 76 (5-8) (2014) 1111-1121.

[20] Y. Huang, M.C. Leu, J. Mazumder, A. Donmez, Additive manufacturing: current state, future potential, gaps and needs, and recommendations, J. Manuf. Sci. Eng. 137 (2015) 014001/1 - 014001/10.

[21] M. Vaezi, S. Chianrabutra, B Mellor, Multiple material additive manufacturing - part 1: a review, J. Virtual Phys. Prototyping 8 (1) (2013) 19-50.

[22] C. Cozmei, F. Caloian, Additive manufacturing flickering at the beginning of existence, Procedia Econ. Finance 3 (2012) 457-462.

[23] I. Gibson, D. Rosen, B. Stucker, Additive Manufacturing Technologies: 3D Printing, Rapid Prototyping, and Direct Digital Manufacturing, 2nd, Springer New York Heidelberg Dordrecht London, 2015 ISBN: 978-1-4939-2112-6.

[24] C. Klahn, B. Leutenecker, M. Meboldt, Design strategies for the process of additive manufacturing, Procedia CIRP 36 (2015) 230-235.
[25] C. Klahn, B. Leutenecker, M. Meboldt, Design for additive manufacturing - supporting the substitution of components in series products, Procedia CIRP 21 (2014) $138-143$.

[26] Roland Berger Strategy Consultants. Additive manufacturing - A game changer for the manufacturing industry? Munich; 2013.

[27] J. Cerneels, A. Voet, J. Ivens, J.P. Kruth, Additive manufacturing of thermoplastic composites, Composites week @ Leuven and TexComp-11 Conference, 2013.

[28] R. Ponche, J.V. Hascoet, O. Kerbrat, P. Mognol, A new global approach to design for additive manufacturing, Virtual Phys. Prototyping 7 (2) (2012) 93-105.

[29] R. Ponche, O. Kerbrat, P. Mognol, J.V. Hascoet, A novel methodology of design for additive manufacturing applied to additive laser manufacturing process, Rob. Comput. Integr. Manuf. 30 (2014) 389-398.

[30] K. Boivie, K. Sorby, V. Brotan, P. Ystgaard, Development of a hybrid manufacturing cell: integration of additive manufacturing with cnc machining, in: 22nd Annual International Solid Freeform Fabrication Symposium - An Additive Manufacturing Conference, Austin, USA, The University of Texas, 2011, pp. 153-163.

[31] G. D’Antonio, F. Segonds, J.S. Bedolla, P. Chiabert, N. Anwer, A proposal of manufacturing execution system integration in design for additive manufacturing, Product Lifecycle Manage. Era Internet Things 467 (2016) 761 770.

[32] M.K. Thompson, A. Stolfi, M. Mischkot, Process chain modeling and selection in an additive manufacturing context, CIRP J. Manuf. Sci. Technol. 12 (2016) 25-34.

[33] U.K.U. Zaman, A. Siadat, M. Rivette, A.A. Baqai, L. Qiao, Integrated product-process design to suggest appropriate manufacturing technology: a review, Int. J. Adv. Manuf. Technol. 91 (2017) 1409-1430.

[34] E.A. Yazdi, J. Gardan, P. Lafon, Integrated design in additive manufacturing based on design for manufacturing, Int. J. Mech. Aerospace Ind. Mechatronic Manuf. Eng. 10 (6) (2016) 1109-1116.

[35] M.A. Maleque, S. Dyuti, Materials selection of a bicycle frame using cost per unit property property and digital logic methods, Int. J. Mech. Mater. Eng. 5 (1) (2010) 95-100.

[36] M.F. Ashby, Material and Process Charts, 2, The CES EduPack Resource Booklet, 2009 (c) Granta Design.

[37] A.F. Berman, G.S. Maltugueva, A.Y. Yurin, Application of case-based reasoning and multi-criteria decision-making methods for material selection in petrochemistry, J. Mater. Design Appl. (2015), doi:10.1177/1464420715620919.

[38] S. Kumar, R. Singh, A system for modeling and material selection for progressive die components, J. Key Eng. Mater. 344 (2007) 873880.

[39] X.F. Zha, A web-based advisory system for process and material selection in concurrent product design for a manufacturing environment, Int. J. Adv. Manuf. Technol. 25 (2005) 233-243.

[40] S. Desai, B. Bidanda, M.R. Lovell, Material and process selection in product design using decision making technique (AHP), European J. Ind. Eng. 6 (3) (2012) 322-346.

[41] N.D. Chakladar, S. Chakraborty, A combined TOPSIS-AHP-method-based approach for non-traditional machining processes selection, J. Eng. Manuf. 222 (2008) 1613-1623.

[42] A. Shanian, A.S. Milani, C. Carcon, R.C. Abeyarante, A new application of ELECTRE III and revised simo's procedure of group material selection under weighting uncertainty, J. Knowl. Based Syst. 21 (2008) 709-720.

[43] C.G. Mancanares, E.S. Zancul, J.C. Silva, P.A.C. Miguel, Additive manufacturing process selection based on parts' selection criteria, Int. J. Adv. Manuf. Technol. (2015), doi:10.1007/s00170-015-7092-4.

[44] A. Armillotta, Selection of Layered Manufacturing techniques by an adaptive AHP decision model, Rob. Comput.-Integr. Manuf. 24 (2007) 450-461.

[45] A. Emrouznejad, M. Marra, The state of the art development of ahp (1979-2017): a literature review with a social network analysis, Int. J. Prod. Res. (2017), doi:10.1080/00207543.2017.1334976.

[46] M. Yazdani, A. Jahan, Analysis in material selection: influence of normalization tools on COPRAS-G, Econ. Comput. Econ. Cybern. Stud. Res. 51 (1) (2017) 59-74.

[47] D. Lukic, M. Milosevic, A. Antic, S. Borojevic, M. Ficko, Multi-criteria selection of manufacturing processes in the conceptual process planning, Adv. Prod. Eng. Manage. 12 (2) (2017) 151-162.

[48] P.R. Adhikari, R. Mirshams, Study of knowledge-based system (KBS) and decisionmaking methodologies in materials selection for lightweight aircraft metallic structures, J. Appl. Sci. Eng. Technol. 5 (1) (2017) 1-19.

[49] M.F. Ashby, Materials selection in mechanical design, Butterworth-Heinemann Linacre House, 3rd, Jordan Hill, Oxford, UK, 2005 ISBN: 0-7506-6168-2.

[50] L. Bechthold, V. Fischer, A. Hainzlmaier, D. Hugenroth, L. Ivanova, K. Kroth, B. Romer, E. Sikorska, V. Sitzmann, 3D printing: a qualitative assessment of applications, recent trends and the technology's future potential, Studien zum deutschen Innovationssystem (2015) 17.

[51] S. Yim, D. Rosen, Build time and cost models for additive manufacturing process selection, in: Proceedings of the ASME 2012 International Design Engineering Technical Conferences \& Computers and Information in Engineering Conference, IDETC/CIE, Chicago, USA, 2012.

[52] T.L. Saaty, Decision making with analytical hierarchy process, Int. J. Serv. Sci. 1 (2008) 83-98.

[53] Adriyendi, Multi-attribute decision making using simple additive weighting and weighted product in food choice, Int. J. Inf. Eng. Electron. Bus. 6 (2015) 8-14. 